3. Phạm Cẩm Phương (2017), "Đánh giá kết quả tư vấn khám sàng loc và phát hiên sớm ung thư vú ở nữ giới tại thành phô Hà Nội và các tỉnh lân cận", Tạp chí y học Việt Nam, Tập 1, tr. 41-45.

4. Phạm Thúy Qừ̀nh (2020), "Kiến thức, thực hành tự khám vú của phụ nữ phường Thượng Cát, quận Bắc Từ Liêm, Hà Nội", Nghiên cứu khoa học khoua học điêu dướng, tập 3 (2), tr. 14-22

5. Trân Văn Thuấn, Bùi Diệu, Nguyễn Bá Đức và cộng sự (2012), "Gánh nặng bệnh ung thư và chiến lược phòng chống ung thư quốc gia đến năm 2020", Tap chí Ung thư học - Hội thảo quốc gia phòng chống ung thư lần thứ 16 tháng 10 năm 2012, Số 1 (2012).

6. Do Quang Tuyen, Truong Viet Dung and et all (2019), "Breast Self-Examination: Knowledge and Practice Among Female Textile Workers in Vietnam", Cancer Control, Vol 26, p 1-7.
7. Donnelly, TT, Khater, AH, Al-Bader, SB (2014). Factors that influence awareness of breast cancer screenina amona Arab women in Oatar: results from a cross sectional survev. Asian Pac J Cancer Prev. 2014;15(23):10157-10164.

8. Hackshaw AK, Paul EA (2003). Breast selfexamination and death from breast cancer: a meta-analysis. $\mathrm{Br}$ J Cancer 2003; 88:1047.

9. Salman AA, Abass BR (2015), Breast Cancer: Knowledge, Attitudes and Practices of Female Secondary School teachers and Students in Samarra City, Iraqi Journal of Cancer and Medical Genetics, Vol 8 (1), pp, 52-59.

10. Thomas DB, Gao DL, Ray RM, et al (2002). Randomized trial of breast self-examination in Shanghai: final results. J Natl Cancer Inst 2002; 94:1445.

\title{
HIỆU QUẢ CỦA PHÁC Đồ ĐIỀU TRI GIẢI ĐộC ETHANOL ĐƯờNG UỐNG Ở BÊ̂NH NHÂN NGộ ĐộC CẤP METHANOL
}

\section{TÓM TẮT}

Mục tiêu: Đánh giá hiệu quả của phác đồ điều trị giải độc ethanol đường uống ở bênh nhân ngộ độc cấp methanol. Đối tượng và phường pháp nghiền cứu: Nghiên cứu mô tá tiến cứu trên có 61 bênh nhânđược chẩn đoán ngộ độc cấp methanol điều trị tại Trung tâm chống độc (TTCĐ) Bệnh viện Bạch Mai từ tháng 10/2016 đến tháng 7/2018 có chỉ định điều trị bằng ethanol $20 \%$ theo phác đô. Kết quả: Tuổi trung bình: 46,7 \pm 15 (16-71) tuổi, nam giới chiếm 93,4\%. Nồng độ methanol máu rất cao, trung vị là $126(20$ - 569,7) mg/dL. Ap dung phác đồ, nồng độ ethanol máu tăng dân, phần lớn (37/61 bệnh nhân) đat muc tiêu sau sau $3,4 \pm 2,36$ giờ $(60,7 \%)$, có $16 / 61$ BN không đạt nồng độ ethanol mục tiêu trong suốt quá trình dùng ethanol $(26,2 \%)$, có $8 / 61 B N$ có thời điểm quá liều ethanol $(13,1 \%)$. Thời gian điều trị trung vị là 4 (1-12) ngày. 28 BN sống không có di chứng (45,9\%), $13 \mathrm{BN}$ có di chứng ( $21,3 \%)$ và $20 \mathrm{BN}$ tử vong chiếm tỉ lê $32,8 \%$. Kết luân: Nghiên cứu cho thây cho thấy việ́c sử dụng phác đồ giải độc bằng ethanol đường uống có hiệu quả trong điều trị ngộ độc methanol. uống.

Tư khoá: ngộ độc cấp methanol, ethanol đường

\section{SUMMARY \\ EFFECTIVENESS OF ORAL ETHANOL THERAPY PROTOCOL IN THE TREATMENT}

*Trung Tâm Chống Đôc - Bênh viên Bạch Mai

Chịu trách nhiệm chính: Đặng Thị Xuân

Email: xuandangthi17@gmail.com

Ngày nhận bài: 19.12 .2020

Ngày phản biên khoa hoc: 22.01.2021

Ngày duyệt bải: 8.2.2021
Đặng Thị Xuân*

OF ACUTE METHANOL POISONINGS

Objective: To evaluate the effectiveness of oral ethanol regimen in the treatment of the patients with acute methanol poisoning. Subjects and methods: The study included 61 patients with acute methanol intoxication treated at Poison Control Center (PCC) of Bach Mai Hospital from October 2016 to July 2018 who were indicated ethanol $20 \%$ orally according to the protocol. Results: Average age was $46.7 \pm 15$ (16-71) years old, male accounted for $93.4 \%$. Blood methanol concentration was very high, median is 126 (20 - 569.7) $\mathrm{mg} / \mathrm{dL}$. Applying the regimen, the blood ethanol concentration gradually increased, the majority (37/61 patients) achieved the target after 3.4 \pm 2.36 hours $(60.7 \%)$, there were $16 / 61$ patients who did not reach the target ethanol concentration $(26.2 \%)$, with 8 out of 61 patients developed ethanol overdose $(13.1 \%)$. Median duration of the treatment was 4 (1-12) days. 28 patients survival (45.9\%), 13 patients with sequelae $(21.3 \%)$ and 20 patients died, accounting for $32.8 \%$. Conclusions: The study showed that the use of an oral ethanol protocol was effective in the treatment of acute methanol poisoning.

Keywords: acute methanol poisoning, oral ethanol

\section{I. ĐĂT VẤN ĐỀ}

Methanol là một loại cồn được sử dụng rộng rãi trong nhiều ngành công nghiệp, trong một số lĩnh vực cuộc sống như làm sơn, lau chùi vecni, dung môi, chất chống đóng băng trong nhiên liệu động cơ đốt trong, dịch rửa kính ô tô... Tuy nhiên, methanol độc tính cao ở người hoàn toàn không được dùng làm rượu thực phẩm.

Uống methanol hay tiếp xúc qua đường hô hấp với số lượng đủ lớn có thể gây ra ngộ độc 
rất nặng. Trên thế giới, theo báo cáo của Tồ chức $Y$ tế thế giới (WHO) trong những năm gần đây có nhiều vụ ngộ độc methanol xảy ra ở nhiêu quốc gia như, Cộng hòa Séc, Ecuador, Estonia, Kenya, Libya, Na Uy..., tỉ lệ tử vong trong khoảng 10-30\%[1]. Ở Việt Nam, số lượng bệnh nhân ngộ độc methanol vào cấp cứu tại Trung tâm Chổng độc bệnh viện Bạch Mai ngày càng gia tăng, tỷ lệ tử vong còn cao $23,3 \%$ 35,2\%[2],[3].

Methanol khi vào trong cơ thể được enzym alcohol dehydrogenase (ADH) tại gan chuyển hóa thành acid formic, là chất rất độc gây toan chuyển hóa và tổn thương nhiêu cơ quan trong bệnh cảnh ngộ độc methanol. Ethanol có ái lực với $A D H$ cao hơn methanol gấp 7-10 lần [4]. Ethanol là một trong hai thuốc giải độc đặc hiệu đã được nhiều nước sử dụng điêuu trị trong ngộ độc methanol [5],[6]. Ở Việt Nam, tại Trung tâm chống độc (TTCĐ) Bênh viện Bạch Mai đã bước đầu sử dụng thuốc giải độc ethanol $20 \%$ đường uống nhưng chưa có nghiên cứu đánh giá hiệu quả của phác đồ. Vì vậy, chúng tôi tiến hành nghiên cứu nàynhằm mục tiêu: Đánh giá hiêuu quả của phác đồ điều trị giải độc ethanol đường uống ở bệnh nhân ngộ độc cấp methanol.

\section{II. ĐỐI TƯợNG VÀ PHƯƠNG PHÁP NGHIÊN CứU \\ 1.1 Đối tượng nghiên cứu}

- Tiêu chuẩn chọn bệnh nhân:Bệnh nhân được chẩn đoán ngộ độc cấp methanol điều trị tại Trung tâm Chông độc bệnh viện Bạch Mai từ tháng 10/2016 đến tháng $7 / 2018$ có chỉ định điêu trị bằng ethanol.

\section{- Tiêu chuẩn loại trừ:}

+ Ngộ độc phối hợp với chất khác ngoài ethanol.

+ Tiền sứ bệnh có di chứng thần kinh trung ương

\subsection{Phương pháp nghiên cứu}

2.2.1. Thiết kế nghiên cứu: Nghiên cứu mô tả tiến cứu

2.2.2. Tiến hành nghiên cứu: Thu thập số liệu theo mẫu bệnh án nghiên cứu:

\section{- Lâm sàng}

+ Thông tin bệnh nhân: tuổi, giới tính, nghề nghiệp, tiền sử bệnh tật

+ Khai thác bệnh sử: triệu chứng lâm sàng, thời điểm uống, thời gian uống tới khi xuất hiện triệu chứng đầu tiên, hoàn cảnh xảy ra ngộ độc.

\section{Cân lâm sàng}

+ Cổng thức máu, sinh hóa máu

+ Khí máu động mạch: $\mathrm{pH}, \mathrm{HCO}_{3}, \mathrm{BE}, \mathrm{PO}_{2}$, $\mathrm{PCO}_{2}$, lactat theo dõi cho tới khi hết toan.

+ Xét nghiêm ethanol và methanol máu khi vào viên và kết thúc lọc máu. Ngoài ra để theo dõi điều trị, ethanol máu được đo sau khi bắt đầu dùng 1 giờ và khi kết thúc lọc máu.

+ Xét nghiệm áp lực thẩm thấu (ALTT) máu vào viện và sau lọc máu, khoảng trông áp lực thẩm thấu (KTALTT), khoảng trống anion.

2.3. Xử lý số liệu. Số liệu được xử lý theo phương pháp thống kê y học, sứ dụng phần mềm SPSS 16.0. So sánh giá trị 2 trung bình bằng Student test (Mann-Witney U test nếu phân bố không chuẩn), so sánh nhiều giá trị trung bình bằng ANOVA test, so sánh tỷ lệ \% bằng test $\mathrm{X} 2$ hoặc Fisher Exact test, mức ý nghĩa thống kê $95 \%$.

\section{KẾT QUẢ NGHIÊN CỨU}

3.1. Đắc điểm chung của các bệnh nhân nghiên cứu. Trong thời gian nghiên cứu (NC), có 61 bệnh nhân (BN) đủ tiêu chuẩn chọn. Tuổi trung bình: 46,7 \pm 15 tuổi, nhỏ nhất là 16 tuổi, cao nhất là 71 tuổi, nhóm tuổi từ 40-59 tuối chiếm thành phần chủ yễu (54,1\%). Trong đó, có $57 \mathrm{BN}$ nam chiếm $93,4 \%$, chủ yếu làm ruộng và lao động tự do là chính chiếm $37,1 \%$ và $31,1 \%$.

\subsection{Một số đặc điểm cận lâm sàng}

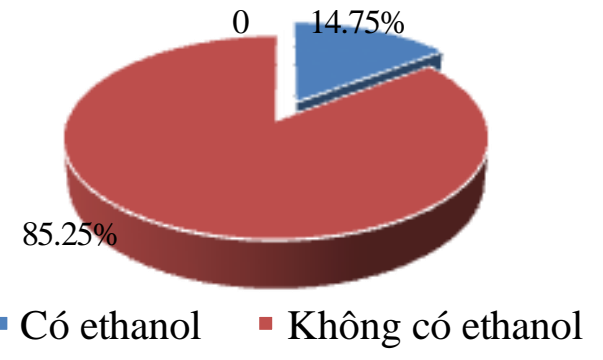

Biểu đồ 3.12: Ethanol máu khi nhập viện

Nhận xét: Phần lớn BN ngộ độc methanol đơn thuần $52 / 61 \mathrm{BN}(85,3 \%)$, có 09 BN $(14,8 \%)$ có cả methanol và ethanol máu khi nhập viện.

Bảng 3.1: Một số triệu chứng cận lâm sàng khi nhập viện

\begin{tabular}{|c|c|c|c|c|}
\hline Triệu chứng & Trung vị & Tứ phân vị & Min & Max \\
\hline Methanol máu $(\mathrm{mg} / \mathrm{dL})(\mathrm{n}=61)$ & 126 & $82,45-183,17$ & 20 & 569,7 \\
\hline $\mathrm{HCO}_{3}(\mathrm{mmol} / \mathrm{l})(\mathrm{n}=61)$ & 4,8 & $3-8,7$ & 3 & 27,9 \\
\hline Lactat máu $(\mathrm{mmol} / \mathrm{L})(\mathrm{n}=61)$ & 5,5 & $1,9-10,35$ & 0,8 & 13,4 \\
\hline Khoảng trống áp lực thấm thấu máu $(\mathrm{n}=38)$ & 65 & $44,25-89,25$ & 12 & 191 \\
\hline Khoảng trống anion $(\mathrm{n}=61)$ & 42 & $33,65-48,85$ & 18 & 107 \\
\hline
\end{tabular}


Nhận xét: - Nồng độ methanol máu rất cao, trung vị là $126 \mathrm{mg} / \mathrm{dL}$, cao nhất 569,7 và thấp nhất là $20 \mathrm{mg} / \mathrm{dL}$.

- Có 38 BN được làm xét nghiệm ALTT máu, KTALTTmáu có khác nhau nhưng tất cả đều tăng, trung vị là 70, cao nhất là 191, thấp nhất là 12 .

- Khoảng trống anion tất cả các BN đều tăng, trung vị là 42 , cao nhất là 107, thấp nhất là 18 ,

- Lactat máu trung vị là 5,5, cao nhất là 13,4, thấp nhất là 0,8 .

- $\mathrm{HCO}_{3}$ trung vị là 4,8 , cao nhất là 27,8 , thấp nhất là 3.

3.3. Hiệu quả của phác đồ Ethanol đường uống

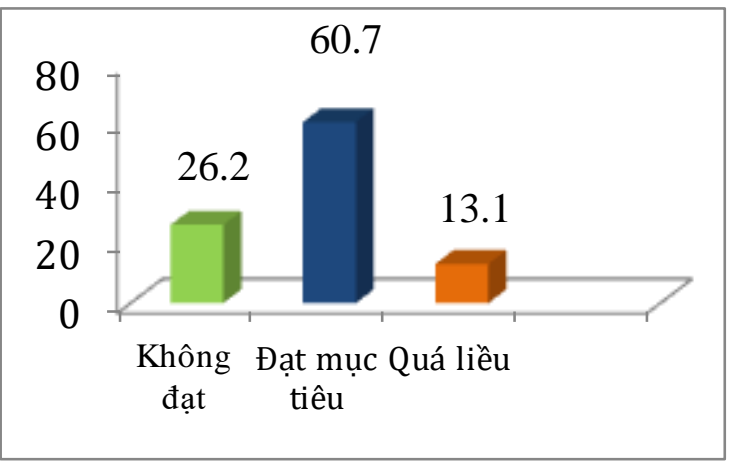

Biểu đồ 1: Hiệu quả đạt nồng độ ethanol muc tiêu theo nhóm bênh nhân

Nhân xét: Trong NC của chúng tôi có 61 BN được dùng ethanol đường uống, chúng tôi thây khi áp dụng phác đồ, nồng độ ethanol máu sẽ tăng dần. Phần lớn 37/61 BN nồng độ ethanol máu tăng dần và đạt mục tiêu sau vài giờ đầu chiếm $60,7 \%$, có $16 / 61$ BN không đạt nồng độ ethanol mục tiêu trong suốt quá trình dùng ethanol $(26,2 \%)$, có $8 / 61 B N$ có thời điểm quá liêu ethanol $(13,1 \%)$

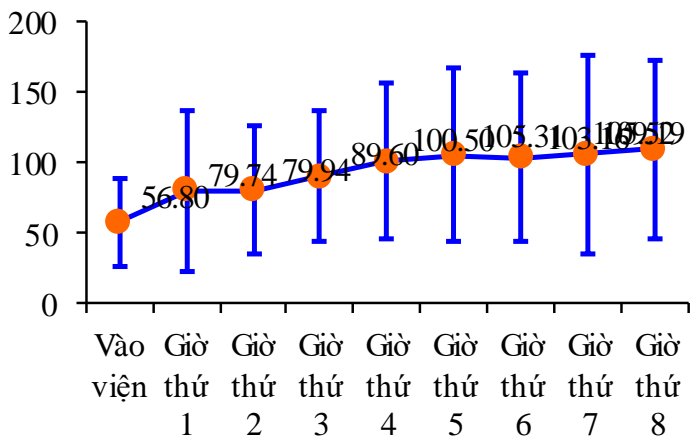

Biểu đồ 2: Diễn biến nồng độ ethanol máu

Nhận xét: Nồng độ ethanol máu tăng dần đến giờ thứ 4 thì đạt nồng độ mục tiêu và duy trì nồng độ mục tiêu đến giờ thứ 8.

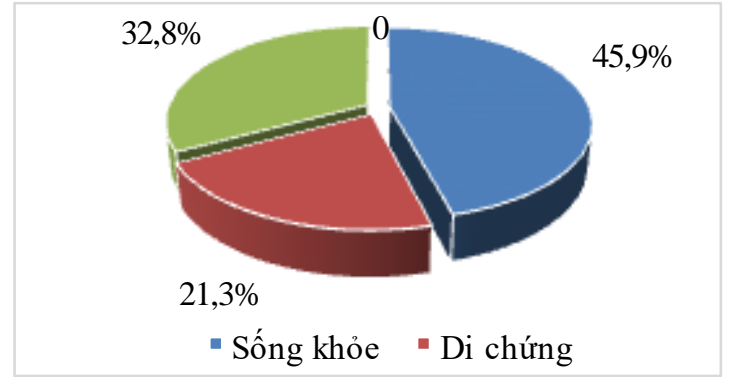

Biêu đồ 3: Kêt quả điều trị

Nhân xét: Trong NC của chúng tôi có 28 BN sống không có di chứng chiếm tỉ lệ 45,9\%, 13 $\mathrm{BN}$ có di chứng chiếm tî lệ $21,3 \%$ và $20 \mathrm{BN}$ tứ vong chiếm tỉ lệ 32,8\%.

Bảng 2: Thời gian nằm viện

\begin{tabular}{|c|c|c|c|c|}
\hline Bệnh nhân & \multicolumn{2}{|c|}{ Thời gian năm viện } & \multirow{2}{*}{$\mathbf{p}$} \\
\cline { 2 - 4 } & Min & Median & Max & \\
\hline $\begin{array}{c}\text { Nghiện rượu } \\
(n=44)\end{array}$ & 1 & 3,5 & 12 & \multirow{2}{*}{0,257} \\
\hline $\begin{array}{c}\text { Không nghiênn } \\
\text { rượu }(n=17)\end{array}$ & 2 & 4 & 12 & \\
\hline Chung $(n=61)$ & 1 & 4 & 12 & \\
\hline
\end{tabular}

Nhận xét: - Thời gian điêuu trị trung vị là 4 ngày, thấp nhất là 01 ngày, nhiêu nhất là 12 ngày.

- Nhóm BN nghiện rượu có thời gian điều trị trung vị là 3,5 ngày (1-12 ngày), nhóm $B N$ không nghiện rượu thời gian điều trị trung vị là 4 ngày (2-12 ngày), khác biệt không có ý nghĩa thống kê với giá trị Mann - Whitney U là 304,5 và $p=0,257>0,05$.

\section{BÀN LUÂN}

\subsection{Một số đặc điểm cận lâm sàng khi} nhập viện

Tình trạng toan máu. Trong quân thể $\mathrm{NC}$ phần lớn BN nhập viện có toan máu (59/61 BN) chiếm $96,72 \%$, trong đó chủ yếu là toan mất bù $(93,44 \%)$ với $\mathrm{pH}=7,13 \pm 0,18$, toan còn bù có 2 BN $(3,28 \%)$, 2 BN $(3,28 \%)$ không có toan máu khi nhập viện. 2 BN chưa có biểu hiện toan máu là $2 \mathrm{BN}$ uống cồn y tế, được đưa đến viện sớm trong vòng 6 giờ đầu sau khi uống. Nghiên cứu của chúng tôi tỉ lệ toan mất bù cũng tương tự NC cửa Beatty tỉ lể có toan mất bù là $100 \%$, pH trung vị là 7,13 , cao hơn nhiều NC Nguyễn Đàm Chính (50\%) [3]. Theo nhận xét của Barceloux, $\mathrm{pH}$ máu dưới 7,25 trong $\mathrm{N} \oplus$ methanol là toan chuyển hóa nặng cần phải lọc máu [7]. NC của chúng tôi cũng phù hợp với NC của Hovda pH trung vị 7,2, của Nohza pH trung vị 7,22 [8].

Ethanol máu khi nhập viện. Tất cả $61 \mathrm{BN}$ của chúng tôi đều được làm xét nghiệm ethanol, methanol máu khi nhập viện, chúng tồi phát hiện 
có 9 BN $(14,75 \%)$ có xét nghiệm ethanol máu dương tính khi nhập viện. Trong đó có 03 BN có ethanol máu nằm trong khoảng $100-150 \mathrm{mg} / \mathrm{dL}$ là nồng độ có thể giúp giải độc methanol, nên 03 BN này có ít triệu chứng khi nhập viện, không có BN nào tử vong và di chứng. Ưu điểm của việc này là $\mathrm{BN}$ có ethanol được coi là có thuốc giải độc một cách tự nhiên, methanol dạng chưa chuyển hóa sẽ được lọc máu ra ngoài trong khi còn chưa gây ra triệu chứng gì. Nhược điểm của việc có ethanol là nhiều $B N$ do có ethanol nên triệu chứng NĐ methanol xuất hiện muộn dẫn đến tâm lý chủ quan làm cho việc nhập viện muộn khi triệu chứng đã nặng. Những BN đến viện mà ethanol dương tính, nhiều khả năng chưa chuyển hóa đến methanol, hoặc mới chuyển hóa một phần do vậy triệu chứng $\mathrm{NĐ}$ methanol có thể nhe hơn.

Các xét nghiệm khác. Có 38/61 BN được làm xét nghiệm ALTT máu tại thời điểm nhập viện. KT ALTi் cũng tăng phù hợp với nồng độ methanol máu, methanol máu càng cao thì ALTT máu càng cao. Kết guả này cũng phù hợp với nghiên cứu của Nguyển Đàm Chính và Phạm Như Quỳnh KT ALTT tăng ở 100\% bệnh nhân [2],[3].

Tại thời điểm nhập viện khoảng trông anion tất cả các $\mathrm{BN}$ trong $\mathrm{NC}$ của chúng tôi đều tăng $(100 \%)$. Kết quả này phù hợp với lý thuyết trong ngộ độc methanol do sản phẩm chuyển hóa cuối cùng của methanol là acid formic sẽ gây ra tình trạng toan chuyển hóa và tăng khoảng trống anion, lượng acid formic càng nhiều thì $\mathrm{KT}$ anion càng cao. BN càng đến muộn, methanol được chuyển hóa thành acid formic càng nhiều thì KT anion càng tăng cao. Do vậy KT anion tỉ lệ thuận với mức độ nặng của bệnh.

Khoảng trống ALTT máu thì tî lệ thuận với nồng độ methanol, khoảng trống anion thì tỉ lệ thuận với lượng acid formic trong máu. Acid formic lại do methanol chuyển hóa tạo thành, như vậy trên $B N$ của chúng tôi, tại thời điểm nhập viện $100 \%$ BN có tăng cả khoảng trống ALTT và khoảng trống anion, điều này chứng tỏ rằng ngoài methanol trong máu đã có một lượng acid formic nhất định được tạo ra từ methanol. Từ đó ta có thể suy luận rằng, lượng methanol thực tế BN uống còn cao hơn rất nhiều lượng chúng tôi định lượng được trong máu.

4.2. Kết quả điêuu trị. Trong nghiên cứu của chúng tôi có 28 BN sống khỏe chiếm tỉ lệ $45,9 \%$, 13 BN sống có di chứng chiếm tỉ lệ $21,3 \%, 20$ BN tử vong chiếm tỉ lệ $32,8 \%$. Mặc dù tỉ lệ tử vong và di chứng của chúng tôi còn cao, nhưng so với các $\mathrm{NC}$ trước đó tại TTCĐ là những $\mathrm{NC}$ mà $\mathrm{BN}$ không được dùng ethanol thì tỉ lệ tử vong, di chứng trong $\mathrm{NC}$ của chúng tôi có giảm. Những $\mathrm{BN}$ di chứng của chúng tôi bao gồm những $B N$ có tổn thương não không hồi phục và giảm thị lực sau khi ra viện. Tuy nhiên số lượng $\mathrm{BN}$ trong NC của chúng tồi còn thấp, thời gian nghiên cứu chưa dài, nên chúng tôi không thể đánh giá hết được ảnh hưởng của di chứng đến cuộc sống của $B N$.

Tất cả $20 \mathrm{BN}$ tử vong của chúng tôi đều thuộc nhóm BN nghiện rượu, có PSS nặng khi vào viện và nồng độ methanol máu rất cao, cao hơn rất nhiêu nồng độ methanol máu trong NC của Zakhazov và Wedge [9]. Dựa vào tỉ lệ tử vong và di chứng chúng ta thấy rằng sử dụng ethanol có thể không làm cải thiện tỉ lệ tử vong, nhưng giúp cải thiện tỉ lệ di chứng ở nhóm sống sót. Điều này phù hợp với lý thuyết, ethanol giúp ngăn chặn hình thành acid formic, mà acid formic chính là thủ phạm gây ra tổn thương ở cơ quan đích là não, là mắt, là thận. Nếu ngộ độc methanol chỉ lọc máu đơn thuần thì trong quá trình lọc máu methanol còn lại vẫn tiếp tục được chuyển hóa để tạo ra acid formic, sử dụng ethanol sẽ ngăn chặn, không tạo ra thêm acid formic, từ đó giảm được các tổn thương do acid formic gây ra.

Thời gian nằm viện: Thời gian nằm viện của BN trong NC của chúng tôi trung vị là 4 ngày, thấp nhất là 01 ngày, nhiều nhất là 12 ngày. Nhóm $\mathrm{BN}$ tử vong có thời gian nằm viện trung vị là 01 ngày, có $01 \mathrm{BN}$ thời gian nằm viện lên đến 04 ngày. Thời gian nằm viên của $B N$ trong NC của chúng tôi tương tự trong NC của Zakhazov, trung vị là 4 ngày, thấp nhất là 01 ngày, cao nhất là 23 ngày. Thời gian nằm viện của $\mathrm{BN}$ trong $\mathrm{NC}$ của Wedge, trung vị là 8 ngày, thấp nhất là 01 ngày, cao nhất là 73 ngày, cao hơn nhiều trong NC của chúng tôi.

So sánh thời gian nằm viện giữa 2 nhóm $B N$ nghiện rượu và BN không nghiên rượu cho thây không có sự khác biệt. Có thể giải thích được điều này là vì nhóm $B N$ nghiện rượu có tới $20 \mathrm{BN}$ vào viện với PSS nặng và tử vong trong thời gian ngắn, do đó là thời gian nằm viện chung của nhóm nghiện rượu ngẳn lại (3,5 ngày), nhóm $\mathrm{BN}$ không nghiện rượu đa số là do uống nhầm nồng độ methanol thấp hơn và vào viện sớm, do đó thời gian điêu trị cũng ngắn (4 ngày).

\section{KẾT LUÂN}

Qua nghiên cứu 61 BN ngộ độc cấp methanol được điều trị bằng dung dịch ethanol $20 \%$ đường uống theo phác đồ tại Trung tâm chống độc bệnh viện Bạch Mai từ tháng 10/2016 đến 
tháng 7/2018 cho thây việc sử dung phác đồ giải độc bằng ethanol đường uống là có hiệu quả. Nồng độ ethanol máu tăng dần, đạt được nồng độ mục tiêu sau 3,4 $\pm 2,36$ giờ, duy trì được cho đến khi hết chỉ định dùng ethanol. Kết quả điều trị có $45,9 \%$ sống không có di chứng, $21,3 \%$ có di chứng và 20 bệnh nhân tử vong chiếm tỉ lệ $32,8 \%$. Thời gian điều trị ethanol đường uống là $8,2 \pm 2,17$ giờ. Thời gian nằm viện trung bình là 4 ngày.

TÀI LIỆ THAM KHẢO

1. Zakhazov $S$, et al. (2015). Fluctuations in serum ethanol concentration in the treatment of acute methanol poisoning: a prospective study of 21 patients. Biomed Pap Med Fac Univ Palacky Olomouc Czech Repub, 159

2. Phạm Như Quỳnh, Lê Đình Tùng, Hà Trân Hứng (2017). Hiểu quả của thẩm tách máu kéo dài trong điều trị bểnh nhân ngộ độc cấp methanol. Tap chí Sinh lý hoc Viêt Nam, 21(3), 13-20.

3. Nguyến Đàm Chính, Hà Trân Hưng (2016). Nhận xét kết quả điều trị bệnh nhân ngộ độc câp methanol taai Trung tâm chống độc bệnh viện Bạch Mai.Tap chí nghiên cứu y hoc,440(1),29-33

4. McMartin K, Jacobsen D, Hovda K.E. (2015). Antidotes for poisoning by alcohols that form toxic metabolites, British Journal of Clinical Pharmacology.

5. Girault C, et al, (1999). Fomepizole (4methylpyrazole) in fatal methanol poisoning with early CT scan cerebral lesions. J Toxicol Clin Toxicol, 37(6), 777-80.

6. Rietjens S.J, D.W. de Lange, and J. Meulenbelt(2014). Ethylene glycol or methanol intoxication: which antidote should be used, fomepizole or ethanol? Neth J Med, 2014. 72(2), 73-9.

7. Barceloux D.G, et al. (2002). American Academy of Clinical Toxicology practice guidelines on the treatment of methanol poisoning. J Toxicol Clin Toxicol, 40(4), 415-46

8. Lee C.Y, et al, (2014). Risk factors for mortality in Asian Taiwanese patients with methanol poisoning. Ther Clin Risk Manag, 10, 61-7.

9. Wedge M.K, et al. (2012). The safety of ethanol infusions for the treatment of methanol or ethylene glycol intoxication: an observational study, Canadian Association of Emergency Physicians CJEM, 14(5), 283-289.

\section{MộT Số YẾU Tố LIÊN QUAN ĐẾN CHİ Số HUYẾT ÁP TÂM THU Cổ CHÂN - CÁNH TAY Ở BỆNH NHÂN BỊ BỆNH ĐộNG MACH CHI DƯớI}

\section{TÓM TẮT}

Hoàn cảnh nghiên cứu: Phương pháp đo chỉ số huyết áp tâm thu cổ chân cánh tay (ABI) với phương tiện và kỹ thuật đơn giản, được khuyến cáo trong sàng lọc và chẩn đoán bênh đông mach chi dưới. Các nghiên cứu trên thế giới cho thấy $A B I$ không những có độ nhạy và độ đặc hiệu cao mà chỉ số này còn tương quan chặt chẽ̃ với mức độ nặng của BĐMCD. Phương pháp nghiên cứu: Là nghiên cứu mô tả cắt ngang trên 158 chi dưới ở 79 bênh nhân bị BĐMCD. Bênh nhân được chụp MSCT động mạch chi dưới, khám lâm sàng và đo chỉ số $A B I$. Sau đó tìm mối liên quan giữa chỉ số $A B I$ với các đăc điểm lâm sàng và tổn thương động mạch chi dưới trên phim chụp MSCT. Kết quả: Trị số $A B I$ thấp hơn có ý nghĩa ở nhóm chi tổn thương từ hai đônng mach trở lên so với nhóm chỉ có tổn thương một động mạch $(p=0,002)$; ở nhóm chi tổn thương từ hai tâng mạch trở lên so với nhóm chỉ có tổn thương một tầng mach $(p=0,01)$; và ở nhóm chi có tắc hoàn toàn lòng động mạch so với nhóm chỉ có hẹp lòng động mạch $(p<0,001)$. Trị số $A B I$ cũng thấp

\section{*Đại Học Y Dược Thái Binh \\ ** Dai Hoc Y Hà Nôi}

Chiu trách nhiệm chính: Trần Xuân Thủy

Email: bsxuanthuyytb@gmail.com

Ngày nhận bài: 4.01.2021

Ngày phản biên khoa học: 26.2.2021

Ngày duyệt bài: 4.3.2021

\section{Trần Xuân Thủy*, Đinh Thị Thu Hương**}

hơn có ý nghĩa ở nhóm chi triệu chứng đau so với nhóm chi không đau $(p=0,001)$; ở nhóm chi có triệu chứng thiếu máu trầm trong so với nhóm chi không có triệu chứng này $(p=0,001)$. Kết luận: Chỉ số $A B I$ tương quan có ý nghĩa với mức độ lâm sàng và mức độ tổn thương động mạch khi đối chiếu với chụp MSCT đông mach chi dưới.

Từ khóa: Bệnh động mạch chi dưới, Chỉ số $A B I$, Chup MSCT.

\section{SUMMARY}

\section{SOME RELATED FACTORS TO ANKLE - BRANCHIAL INDEX (ABI) IN PATIENT WITH LOWER EXTREMITY ARTERY DISEASE}

Background: The ankle - branchial index (ABI) is simple to performed, so it is recommended to screen and early diagnose the lower extremity artery disease (PAD). Beside the high sensitivity and the high speccificity, rearches in the world has shown that ABI have close relationship to the severity of PAD. Subjects and Methods: A Cross-sectional study on 158 lower limbs of 79 patients with lower extremity artery disease. Patients were performed lower lim artery MSCT, took medical history, clinical examined and measured ABI. Then, we finded the relationship of $A B I$ to clinical characteristics and subcliniccal characteristics on MSCT. Results: ABI was significantly lower in the limbs with $\geq 2$ sick arteries in compare to limbs with one sick artery $(p=0,002)$, in the limbs with $\geq 2$ sick artery floors in compare to 